J. Biosci., Vol. 15, Number 3, September 1990, pp. 117-123. (C) Printed in India.

\title{
Nuclear magnetic resonance and thermal studies of drug doped dipalmitoyl phosphatidyl choline- $\mathrm{H}_{2} \mathrm{O}$ systems
}

\author{
K. USHA DENIZ ${ }^{\dagger \S}$, P. S. PARVATHANATHAN ${ }^{\dagger}$, GEETA DATTA ${ }^{\dagger \dagger}$, \\ C. L. KHETRAPAL, K. V. RAMANATHAN, N. SURYAPRAKASH \\ and S. RAGHOTAMA \\ Sophisticated Instrument Facility, Indian Institute of Science, Bangalore 560 012, India \\ $\uparrow$ Nuclear Physics Division and ††Biochemistry Division, Bhabha Atomic Research Centre, \\ Trombay, Bombay 400 085, India
}

\begin{abstract}
The influence of the sulfone drugs, diamino diphenyl sulfone and diamino monophenyl sulfone on the phase transitions and dynamics of dipalmitoyl phosphatidyl choline- $\mathrm{H}_{2} \mathrm{O} / \mathrm{D}_{2} \mathrm{O}$ vesicles have been investigated using differential scanning calorimetry and nuclear magnetic resonance. Our results show that diamino diphenyl sulfone interacts quite strongly with the headgroups of dipalmitoyl phosphatidyl choline whereas the diamino monophenyl sulfone-dipalmitoyl phosphatidyl choline interaction is quite weak. This is attributed to the difference in the structure and hydrophobic character of the two drugs.
\end{abstract}

Keywords. Dipalmitoyl phosphatidyl choline; drug-membrane interaction; differential scanning calorimetry; ${ }^{1} \mathrm{H}$ NMR; ${ }^{31} \mathrm{P}$ NMR.

\section{Introduction}

Study of interactions of drugs with biomembrane is of great importance. Biomembranes being very complex, one studies interactions of drugs with modelmembranes as a first step towards understanding drug-biomembrane interactions. In the present work, we have carried out differential scanning calorimetry (DSC) and nuclear magnetic resonance (NMR) $\left({ }^{1} \mathrm{H}\right.$ and $\left.{ }^{31} \mathrm{P}\right)$ experiments at temperatures in the vicinity of the chain melting (CM) transition to observe the interaction of the sulfone drugs, diamino diphenyl sulfone (DDS or Dapsone) and diamino monophenyl sulfone (DMS or sulfanilamide) with the model membrane, dipalmitoyl phosphatidyl choline (DPPC) $-\mathrm{H}_{2} \mathrm{O} / \mathrm{D}_{2} \mathrm{O}$, in vesicle form. These drugs are expected to possess distorted tetrahedral structures (figure 1). Though DDS has been in use as an antileprosy drug for a few decades, hardly any information about its interactions with membranes was available until recently (Deniz et al., 1983, 1989). While our main interest was in DDS-membrane interactions, DMS was used in order to understand how structural differences affect these interactions.

\section{Materials and methods}

DPPC and DMS were purchased from Sigma Chemical Company, St. Louis, Missouri, USA, while DDS was a gift from Burroughs Wellcome India. These were

$\S$ To whom all the correspondence should be addressed.

Abbreviations used: DSC, Differential scanning calorimetry; NMR, nuclear magnetic resonance; CM, chain melting; DDS, diamino diphenyl sulfone; DPPC, dipalmitoyl phosphatidyl choline; PT, pretransition. 


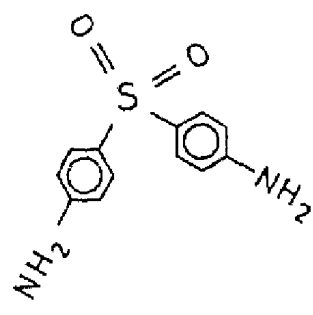

DDS

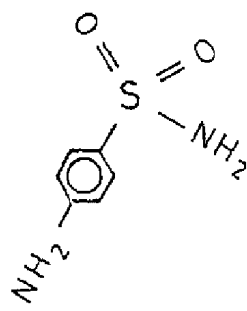

DMS

Figure 1. The structure of ,molecule, DDS and DMS.

used without further purification. The vesicles of DPPC and drug-DPPC were prepared by hydrating their films with $\mathrm{H}_{2} \mathrm{O} / \mathrm{D}_{2} \mathrm{O}$ at $45^{\circ} \mathrm{C}$, vorticising them and subsequently sonicating at $45^{\circ} \mathrm{C}$ for $45 \mathrm{~min}$, using a microtip. DPPC concentration, [DPPC], of $50 \mathrm{mM}$ and a molar ratio, $R_{m}$, of drug to DPPC of 0.1 were used. The DSC studies were carried out on a Perkin Elmer DSC-2C instrument. Sample weights ranged from $10-16 \mathrm{mg}$ and the scans were carried out at rates of 2.5-10 K/min. ${ }^{1} \mathrm{H}$ NMR at $270 \mathrm{MHz}$ was carried out on a Bruker WH 270 instrument with sodium-3-trimethylsilyl $\left(2,2,3,3-{ }^{2} \mathrm{H}\right)$ propionate (TSP) as reference and ${ }^{31} \mathrm{P}$ NMR at $121.44 \mathrm{MHz}$ was done on a Bruker MSL 300 instrument with phosphoric acid as reference.

\section{Results and discussion}

$D S C$

The model membrane, DPPC- $\mathrm{H}_{2} \mathrm{O} / \mathrm{D}_{2} \mathrm{O}$ exhibits an ordered lamellar gel $\left(L_{\beta}{ }^{\prime}\right)$ phase at room temperature. On heating, a pre-transition (PT) occurs to a ripple phase $\left(\mathrm{P}_{\beta^{\prime}}\right)$ (Janiak et al., 1976; Scott, 1981). This is followed by a CM transition into a disordered liquid crystalline $\left(L_{\alpha}\right)$ phase. This transition is of physiological importance, since the chain mobility (membrane function) is related to it.

DSC scans through the CM transitions for the 3 systems are shown in figure 2. We find that (i) $T_{\mathrm{CM}}$ is slightly increased in the presence of DDS but is slightly decreased by DMS and (ii) PT (not seen in the figure) is suppressed completely by DDS but only partially by DMS. This can be explained in the following way. Due to the tetrahedral structure of the DDS molecule and its amphiphilic nature, one would expect [in the light of De Verteuil et al. (1981) theory] a significant decrease in $T_{\mathrm{CM}}$, if DDS were to be located in the acyl chain region. Since it is not observed, DDS must be located at the DPPC- $\mathrm{H}_{2} \mathrm{O}$ interface, interacting with the polar head group of the lipid and enhancing the effective DPPC head group-head group interaction. This can account for the observed increase in $T_{\mathrm{CM}}$ (De Verteuil et al., 1981). DMS being more polar than DDS, is less likely to enter the acyl chain region. However, it must be decreasing slightly, the effective interaction between DPPC head groups, leading to the observed decrease in $T_{\mathrm{CM}}$. The values of $T \mathrm{~cm}$ and $\Delta H_{\mathrm{CM}}$ measured with stacked bilayers (Deniz et al., 1983) of these 3 systems, differ from those obtained in the present measurements with vesicles (table 1). It is observed that (a) $\Delta H_{\mathrm{CM}}$ is drug-independent in stacked bilayers but is drug-dependent in vesicles and (b) in DPPC- $\mathrm{H}_{2} \mathrm{O}, \Delta H_{\mathrm{CM}}$ (vesicle) $« \Delta H_{\mathrm{CM}}$ (stacked 


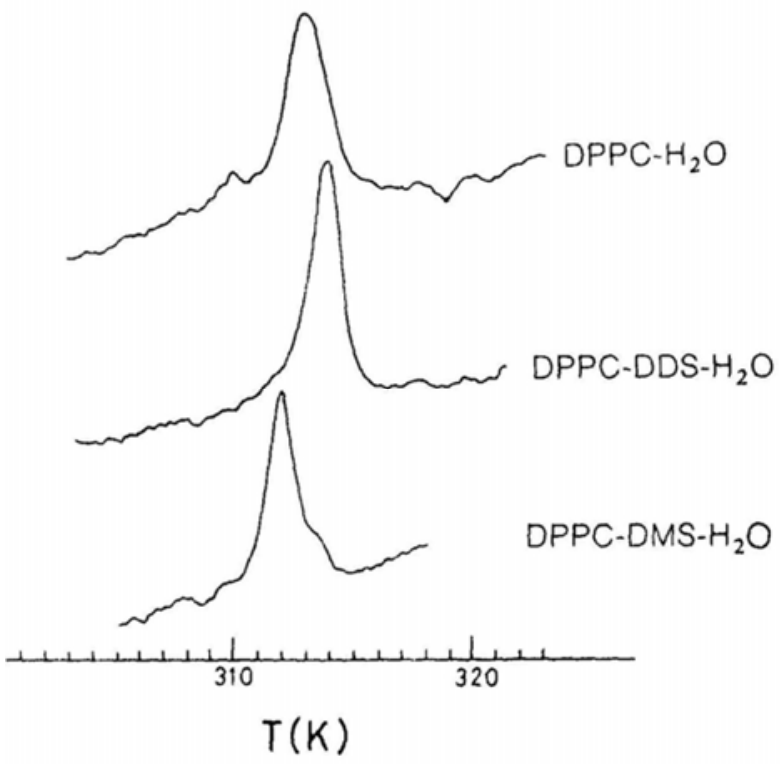

Figure 2. DSC scans of the 3 model membranes, DPPC- $\mathrm{H}_{2} \mathrm{O}$, DPPC-DDS- $\mathrm{H}_{2} \mathrm{O}$ and DPPC-DMS- $\mathrm{H}_{2} \mathrm{O}$ showing the CM transition (scan rate: $2 \cdot 5 \mathrm{~K} / \mathrm{min}$ ).

Table 1. $T_{\mathrm{CM}}$ and $\Delta H_{\mathrm{CM}}$ for various model membrane systems.

\begin{tabular}{lcccccc}
\hline & \multicolumn{3}{c}{ Stacked bilayers } & & \multicolumn{2}{c}{ Vesicles } \\
\cline { 2 - 3 } \cline { 6 - 7 } & \multicolumn{2}{c}{$\begin{array}{c}T_{\mathrm{CM}} \\
\text { Systems }\end{array}$} & $\begin{array}{c}\Delta H_{\mathrm{CM}} \\
(\mathrm{K} \mathrm{Cal} / \mathrm{mol})\end{array}$ & & $\begin{array}{c}T_{\mathrm{CM}} \\
(\mathrm{K})\end{array}$ & $\begin{array}{c}\Delta H_{\mathrm{CM}} \\
(\mathrm{KCal} / \mathrm{mol})\end{array}$ \\
\hline DPPC- $\mathrm{H}_{2} \mathrm{O}$ & 313.7 & 8.44 & & 312.8 & 4.42 \\
DPPC-DMS- $\mathrm{H}_{2} \mathrm{O}$ & 312.4 & 9.56 & & 314.8 & 5.39 \\
DPPC-DDS- $\mathrm{H}_{2} \mathrm{O}$ & 312.9 & 8.41 & & 314.0 & 7.01 \\
\hline
\end{tabular}

bilayer). In vesicles which arc unilamellar or made up of only a few lamellae (i) it is easier for the drug to have access to the DPPC-head group than in stacked bilayer and this could account for (a), (ii) increased fluctuations in the order parameter of the gel phase near $T_{\mathrm{CM}}$ reduces $\Delta H_{\mathrm{CM}}$ resulting in (b) and (iii) these order parameter fluctuations might be reduced by the drug-DPPC interactions leading to $\Delta H_{\mathrm{CM}}$ (DPPC-DDS- $\left.\mathrm{H}_{2} \mathrm{O}\right)>\Delta H_{\mathrm{CM}}\left(\right.$ DPPC- $\left.\mathrm{H}_{2} \mathrm{O}\right)$ (observation (a)).

\section{${ }^{1} H N M R$}

${ }^{1} \mathrm{H}$ NMR spectra for DPPC in the 3 model membranes are shown in figure 3 . In DPPC- $\mathrm{D}_{2} \mathrm{O}$ (figured 3A), the chain resonances, (1)-(4) and the choline group resonances, (5)-(7) are clearly visible at $315 \mathrm{~K}$. The chain resonances are seen to be very broad and unresolved at 310 and $312 \mathrm{~K}$. They begin to get resolved at $313 \mathrm{~K}$, showing that $312 \mathrm{~K}<T_{\mathrm{CM}}<313 \mathrm{~K}$. The $\mathrm{N}^{+}\left(\mathrm{CH}_{3}\right)_{3}$ resonance, (5) is sharp even at $310 \mathrm{~K}$, indicating that these methyl groups are quite mobile not only for $T>T_{\mathrm{CM}}$ but also for $T<T_{\mathrm{CM}}$ Resonance (5) consists of two peaks, (5)' and (5)" corresponding to the choline groups of the outer and inner leaflets of the bilayer. 


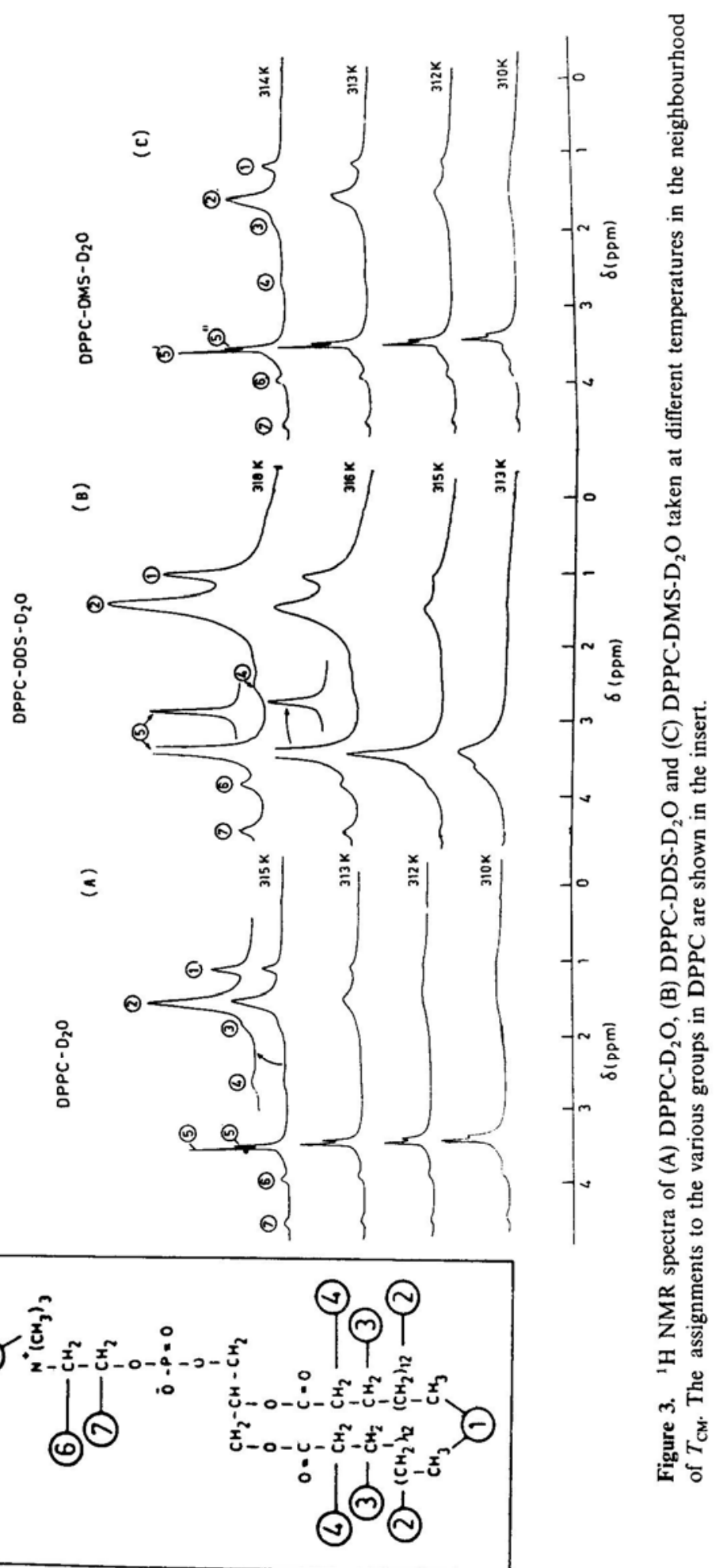


The spectra for DPPC-DMS- $\mathrm{D}_{2} \mathrm{O}$ (figure 3B) closely resemble those of DPPC- $\mathrm{D}_{2} \mathrm{O}$ except that $T_{\mathrm{CM}}$ is slightly decreased $\left(T_{\mathrm{CM}} \approx 312 \mathrm{~K}\right)$. The spectra for DPPC-DDS$\mathrm{D}_{2} \mathrm{O}$ (figure 3C) shows the following: (i) The chain resonance (1), (2) and (4) can be seen at $318 \mathrm{~K}$, but resonance (3) is not observed, possibly due to the broadening of the $\left(\mathrm{CH}_{2}\right)_{\mathrm{n}}$ resonance, (ii) The $\mathrm{CM}$ transition in this case, occurs between 315 and $316 \mathrm{~K}$, i.e., $T_{\mathrm{CM}}$ (DPPC-DDS- $\left.\mathrm{D}_{2} \mathrm{O}\right)>T_{\mathrm{CM}}$ (DPPC- $\left.\mathrm{D}_{2} \mathrm{O}\right)$. (iii) Although all the 3 choline resonances, (5)-(7) can be seen, (5) is a single peak even at $T>T_{\mathrm{CM}}$, unlike in the other two cases. This would mean that the chains and the $\mathrm{N}^{+}\left(\mathrm{CH}_{3}\right)_{3}$ groups become more rigid in the presence of DDS. These results suggest that DDS interacts with the choline groups and perhaps also the carbonyl group of DPPC, the latter leading to decreased chain mobility.

The ${ }^{1} \mathrm{H}$ NMR spectra of the aromatic protons of (i) DDS in $\mathrm{D}_{2} \mathrm{O}$, (ii) DDS in DPPC- $\mathrm{D}_{2} \mathrm{O}$ and (iii) DMS in DPPC- $\mathrm{D}_{2} \mathrm{O}$ are shown in figure 4, the latter two for temperatures in the vicinity of $T_{\mathrm{CM}}$. The aromatic proton spectra for DDS in $\mathrm{D}_{2} \mathrm{O}$ and DMS in $\mathrm{D}_{2} \mathrm{O}$ are similar, consisting of two doublets. This doublet structure (the spin coupling constant) is temperature independent for the temperature range used in these experiments. In DPPC-DMS- $\mathrm{D}_{2} \mathrm{O}$, the doublet structure is hardly changed. However, in DPPC-DDS- $\mathrm{D}_{2} \mathrm{O}$, these resonances are broadened and the doublets cannot be resolved, showing that the aromatic rings of DDS are also interacting with DPPC.

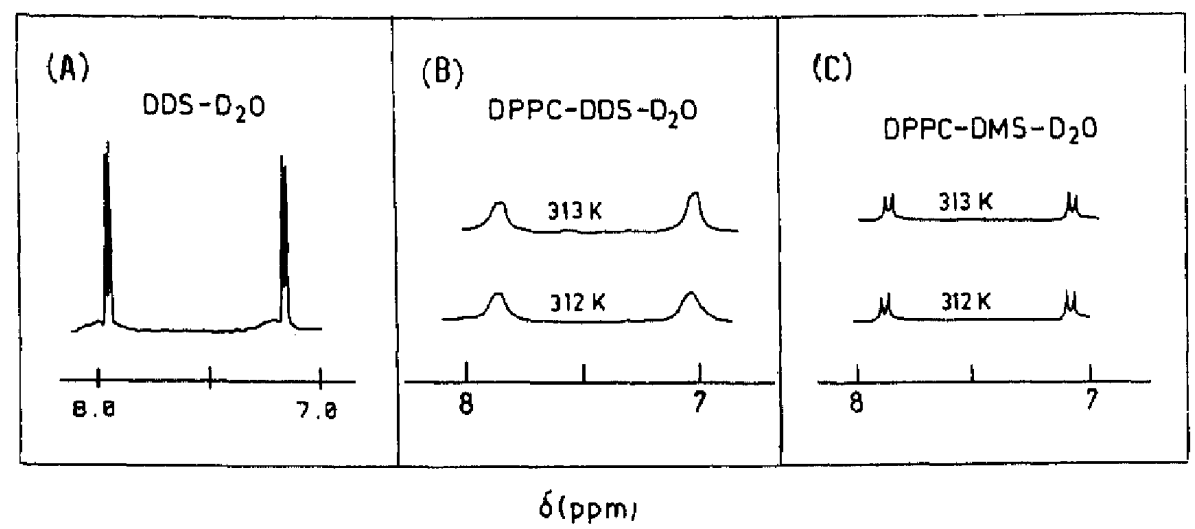

Figure 4. ${ }^{1} \mathrm{H}$ NMR spectra of the aromatic protons in (A) DDS- $\mathrm{D}_{2} \mathrm{O}$, (B) DPPC-DDS$\mathrm{D}_{2} \mathrm{O}$ and $(\mathrm{C})$ DPPC-DMS- $\mathrm{D}_{2} \mathrm{O}$. (B) and (C) are given for temperatures $\approx T_{\mathrm{CM}}$.

${ }^{3} P N M R$

A ${ }^{31} \mathrm{P}$ NMR study of DPPC- $\mathrm{D}_{2} \mathrm{O}$ and DPPC-DDS- $\mathrm{D}_{2} \mathrm{O}$ was carried out as a function of temperature. Typical spectra for $T<T_{\mathrm{CM}}$ and $T>T_{\mathrm{CM}}$ are shown in figure 5. For the drug-free system, the resonance is very sharp for both the temperatures, whereas in the presence of DDS, these resonances are broadened considerably even for $T>T_{\mathrm{CM}}$. This indicates that DDS $\left(\mathrm{NH}_{2}\right.$ group) interacts with the phosphate group of DPPC.

Our results show that DDS-DPPC interaction is much stronger than that of 


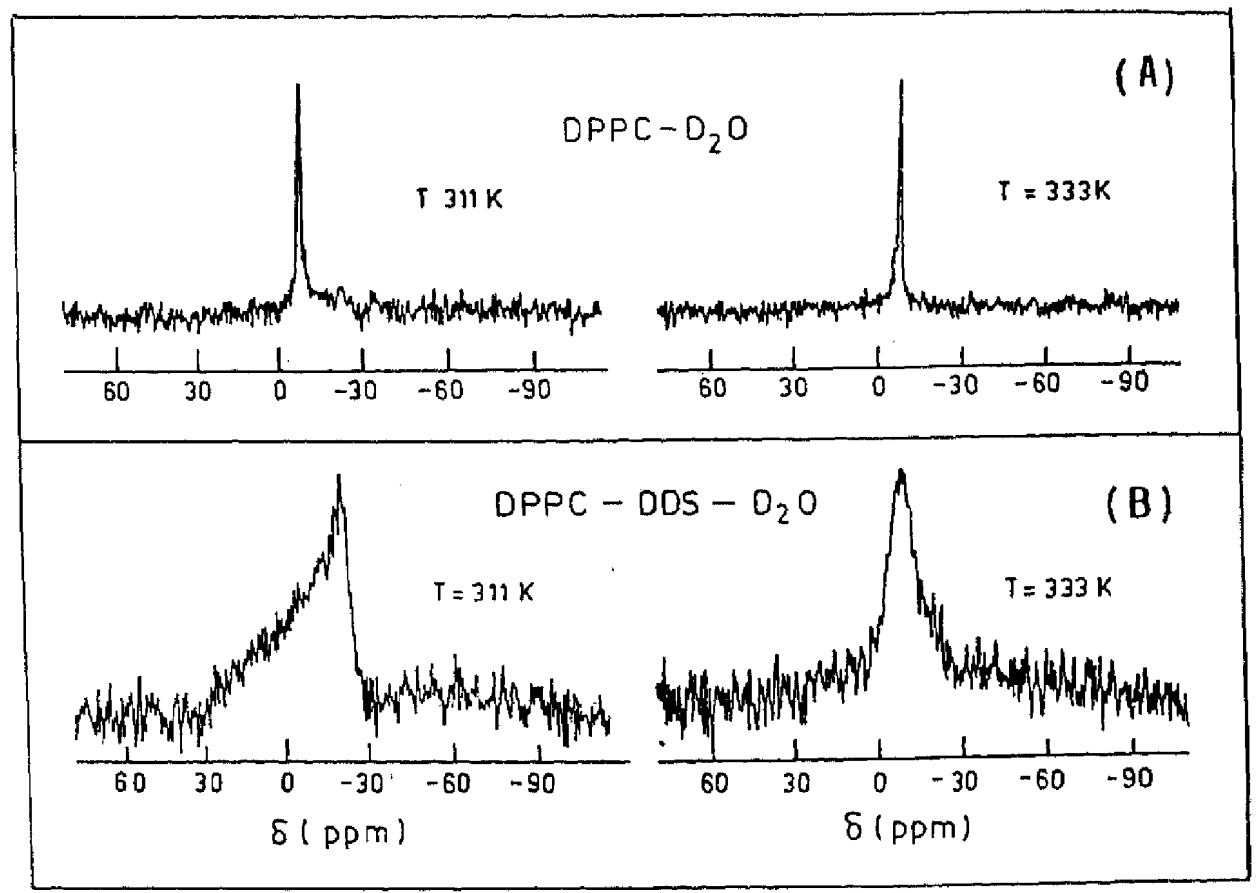

Figure 5. ${ }^{31} \mathrm{P}$ NMR spectra of (A)DPPC- $\mathrm{D}_{2} \mathrm{O}$ and (B) DPPC-DDS- $\mathrm{D}_{2} \mathrm{O}$, for $T<T_{\mathrm{CM}}$ and $T>T_{\mathrm{CM}}$.

DMS with DPPC. The aromatic as well as polar groups of DDS interact with DPPC head group. The most likely interactions are shown below:

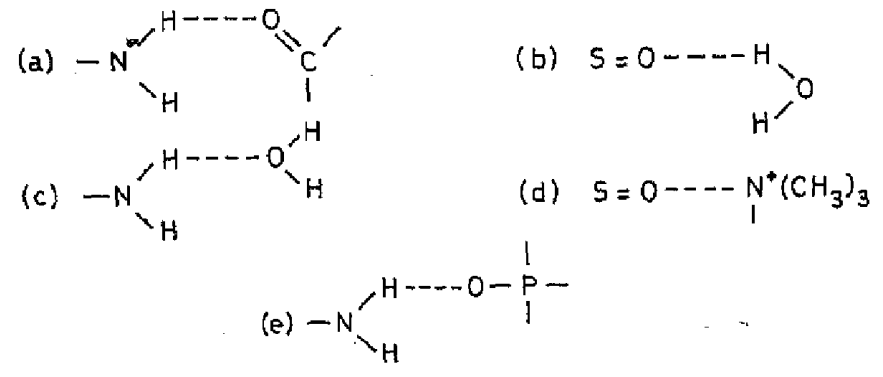

Probable combinations of these are (a) $+(b),(c)+(d)$ and (a) $+(d)$.

The difference between the DDS-DPPC and DMS-DPPC interactions could be due to (i) more polar character of DMS leading to its greater solubility in water and weaker interactions with DPPC and (ii) molecular structure of DDS which would allow its interactions with the head groups of neighbouring DPPC molecules whereas the same would not be possible with DMS.

\section{Acknowledgement}

We are grateful to Burroughs Wellcome India Ltd. for the gift of DDS. 


\section{References}

Deniz, K. U., Parvathanathan. P. S., Mirza, E. B., Amirthalingam, V., Muralidharan, K. V. and Gurnani, S. (1983) Mol. Cryst. Liq. Cryst., 98, 163.

Deniz, K. U., Parvathanathan, P. S., Datta, G. and Mirza, E. B. (1989) in Surfactants in solution (ed. K. L. Mittal) (New York: Plenum) vol. 8, p. 203.

De Verteuil, F., Pink, D. A., Vadas, E. B. and Zuckermann, M. J. (1981) Biochim. Biophys. Acta, 640, 207. Janiak, M. J., Small, D. M. and Shipley, G. G. (1976) Biochemistry, 15, 4575.

Scott, Jr., H. D. (1981) Biochim. Biophys. Acta, 643, 161. 